ScIDice

\section{International Journal of Dentistry and Oral Science (IJDOS)}

ISSN: $2377-8075$

\title{
Genetics And Smoking Cessation - An Overview
}

\section{Leelavathi ${ }^{1 *}$, Dhanraj Ganapathy ${ }^{2}$}

${ }^{1}$ Senior lecturer, Department of Public Health Dentistry, Saveetha Dental College and Hospitals, Saveetha Institute of Medical and Technical Sciences, Saveetha University, Chennai-77,India.

${ }^{2}$ Professor and Head, Department of Prosthodontics, Saveetha Dental College and Hospitals, Saveetha Institute of Medical and Technical Sciences, Saveetha University, Chennai-77, India.

\section{Abstract}

\begin{abstract}
Smoking is the major cause of preventable death worldwide. Behavioural and pharmacological treatments are available for smoking cessation. Nicotine replacement therapies such as nicotine gums, inhaler, nicotine patches; bupropion and varenicline are widely for curbing tobacco use among smokers. However, in spite of these treatment modalities, not every smoker succeeds in quitting the habit of smoking. Nicotine dependence among smokers is decided by the interaction of various factors including environmental factors and genetic factors. Various studies been done on genetic variation in nicotine-metabolizing enzymes and the role of genetics on nicotine dependency is been reported in these studies. Tobacco cessation would be more effective if the role of genetic factors been studied and used in practice. Hence this review was done with an aim to assess the genetic variation in nicotine dependency among tobacco users.
\end{abstract}

Keywords: Nicotine; Pharmacogenetic; Tobacco Cessation; Addiction; Nicotine Replacement.

\section{Introduction}

Tobacco usage remains the important preventable cause of premature morbidity and mortality all over the world. Various researches were done on the ill effects of tobacco usage and smoking cessation treatments has contributed to reductions in smoking prevalence. Nevertheless, there are currently still more than 1.2 billion smokers world-wide, resulting in 3-4 million deaths per year and the development of many smoking-related diseases, including cancers, cardiovascular, diabetes etc. Smoking and tobacco related illness and mortality could be prevented $[1,2]$.

Nicotine replacement therapies available as nicotine gums, nicotine patches, lozenges, inhalers nasal sprays provide nicotine to the brain. Nicotine replacement therapies are either prescribed by the health care professionals or available as over the counter drugs[3].

In spite of the self-treatments and professional guidance on smoking cessation not all the smokers succeeded in quitting the habit with greater relapse rates. Behavioural management and pharmacological treatment of smoking cessation revealed that the success of available treatments is limited. Only 5-30\% of the smokers succeeded in quitting[1].

Addiction to tobacco use and success in quitting the habit is influenced by genetic factors. 5e9 Difference in the genetic factors may have an effect on the response of the smoker for behavioural counselling, nicotine replacement therapies or other pharmacological treatments [4].

\section{Nicotine Addiction And Tobacco Use}

Drug addiction is the self-administration of the drug repeatedly and also finding difficult to stop the habit even though they are advised to stop. Nicotine dependence is the major factor that make the smokers to maintain the habit. Based on the dependence of nicotine, the success of cessation program varies and also, they experience different level of withdrawal symptoms[5].

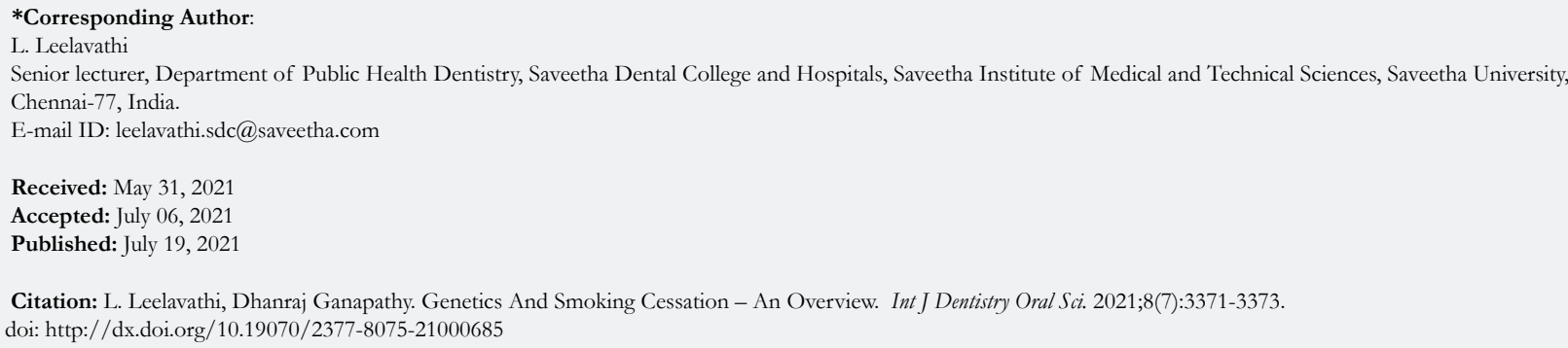

Copyright: L. Leelavathi ${ }^{\circ} 2021$. This is an open-access article distributed under the terms of the Creative Commons Attribution License, which permits unrestricted use, distribution and reproduction in any medium, provided the original author and source are credited. 
Nicotine attaches to ligand gated ion channels nAChRs, which plays a vital role in neuronal integration, excitability of cells and release of transmitters. Thus, mesocorticolimbic dopamine system gets activated which plays a role in induction of aversion or reward[6].

Smokers use tobacco products to regulate their mood as nicotine in cigarettes decrease the anxiety, stress and promotes comfort. Hence cessation of the habit increases stress, anxiety and cause restlessness and depressed mood. It is been reported that these mood changes are similar to that found in psychiatric patients [7, $8,9,10]$.

\section{Genetic Influences On Smoking Persistence And Relapse}

Smoking habit are reported to begenetic in the studies conducted among the twins. They found the difference in the initiation of the tobacco habit, persistence and also the nicotine dependence and smoking cessation vary based on the genetic factors[11].

Studies to find the relation between smoking and genetics was first reported in 1958. Genetics play a role in predisposing the individual to tobacco usage and occurrence of pulmonary cancer thus suggesting that genetics is associated with tobacco usage and neoplasm of the lung. Numerous twin studies enumerate the role of genetics in tobacco addiction and monozygotic twins had similar addiction level when compared with dizygotic twins.

Variation in the genes in the dopamine pathway provide biological variation on tobacco dependence, as dopamine is involved in the rewarding effect. Nicotine activates certain receptors and arouses the dopamine release in the accumbens nucleus[11].

\section{CYP2A6 And Tobacco Dependence}

Cytochrome P450 2A6 (CYP2A6) is responsible for the metabolism of nicotine into cotinine. CYP2A6 is believed to be the most important predictor of the rate of nicotine metabolism, as it is responsible for aroundninety percent of the metabolic inactivation of nicotine to cotinine. Several studies have shown that individuals carrying CYP2A6 variants that reduce the enzyme activity have decreased tobacco dependence, smokes significantly fewer cigarettes per day and have an increased likelihood of quitting the habit $[55,58-62]$. Few studies done to find the association of CYP2A6 genetic variants and tobacco dependence, number of cigarettes smoked per day reported that there was no association $[12,13]$.

Nicotine is metabolized to cotinine, mainly by CYP2A6.1 Various CYP2A6 gene polymorphisms have been determined as of now, and three alleles, $* 1, * 4$ and $* 9$, are shown to be the major CYP2A6 polymorphisms in Japanese population. CYP2A6*1 is a wild-type allele reported to have normal enzyme activity. CYP2A6*4 is a whole deletion type of the CYP2A6 gene.2,3 CYP2A6*9 has a single-nucleotide polymorphism which destroys the transcriptional activities and enzymatic activity. It has been clearly established that the CYP2A6 polymorphisms influence the pharmacokinetics of nicotine[12,14].

\section{DRD2 And DAT1 Genes And Tobacco Depend-} ence

Nicotine activates the mesolimbic dopamine system and is especiallyessential in addictive behaviors. As a consequence, genes encoding proteins involved in the neurotransmission of dopamine have been considered possible candidate genes for nicotine dependence and smoking cessation, and they have been widely studied in candidate gene studies. Variations of the dopa-mine receptor D2 (DRD2) and DAT1 genes have received specific attention $[8,15,16,17]$.

several pharmacogenetic studies have suggested an association between genes involved in the dopaminergic pathway and response to pharmacotherapy that is aimed at smoking cessation Variants in several dopamine receptor genes such as DRD1, DRD2, DRD4 and DRD5have been identified and studied in relation to smoking habit. Genotypes related with decreased dopamine receptor expression or function seem to predict a greater chance of becoming a tobacco user, initiation of the habit at younger age, and fewer successful quit attempts. This is probably because subjects with decreased numbers of dopamine receptors may compensate for this defect by using nicotine to raise brain dopamine levels. However, the evidence regarding such results is still not conclusive[12].

Several studies have reported that the A1 allele of the DRD2 Taq1A polymorphism is associated with age of smoking initiation, being a former or current smoker and smoking intensity[8].

\section{CHRNA5 And Tobacco Dependence}

The first gene study to report relation between the nicotine dependence and SNP rs16969968 in CHRNA5 was done by Sacconeandcollegues[8].

Chen and colleagues conducted a large study to determine genetic associations with age of cessation. CHRNA5-A3-B4 risk haplotypes (rs16969968 and rs680299, both in CHRNA5) were found to be associated with the number of cigarettes smoked per day and a later quitting age; [8] The variant rs16969968 of CHRNA5 was reported to have possible ability to predict delay in tobacco cessation[18]. Whereas in a study conducted by Tyndale et al to determine the association between smoking abstinence and CHRNA5- A3-B4 haplotypes, it was reported that there was no association between smoking abstinence and CHRNA5 haplotypes among the study participants who received Nicotine replacement therapy, placebo or varenicline[19]. Ware and colleaguesdid a secondary analysis of data from a randomised controlled trial of smoking cessation. It was reported that rs1051730 is associated with adherence to nicotine replacement treatment after 7 days of the quit attempt but however the association was notreported after 28 days $[8,20]$.

A study was done to assess the smoker's intention for undergoing genetic testing for tobacco cessation and it was found that very a smaller number of participants $(16.6 \%)$ were completely interested in undergoing a genetic test to decideabout the selection of smoking cessation therapy and the remaining participants were either not interested or not certain about the genetic testing for 
smoking cessation [4]. Genetic studies for finding the influence of genetic factors on tobacco dependence was done with an intention to identify the difference in an individual towards tobacco addiction and thus provide them the needed guidance and treatment. But practical applications of these genetic testing will be based on the acceptance of these tests by the individual person[6]. At present, there is relatively little knowledge about the willingness and preferences of smokers concerning genetic testing for tobacco addiction and cessation and about individuals' knowledge and attitudes[4].

\section{Conclusion}

Though there was an increase in the quitting of the tobacco due to pharmacotherapies and behavioural counselling, still many of the tobacco users have been finding it difficult to completely quit the habit. Various studies been conducted on nicotine addiction and the role of genetic factors on nicotine addiction to be studied at different aspects, which will help in preventing the mortality caused by tobacco and related products.

\section{References}

[1]. Frederik-Jan van Schooten et al, Assessment of genetic variations as a predictor for smoking cessation and health risks.

[2]. deViron S, Van der Heyden J, Ambrosino E, Arbyn M, Brand A, Van Oyen $\mathrm{H}$. Impact of genetic notification on smoking cessation: systematic review and pooled-analysis. PLoS One. 2012;7(7):e40230. PubmedPMID: 22808123

[3]. Wadgave U, Nagesh L. Nicotine Replacement Therapy: An Overview. Int J Health Sci (Qassim). 2016 Jul;10(3):425-35. PubmedPMID: 27610066.

[4]. Quaak M, Smerecnik C, van Schooten FJ, de Vries H, van Schayck CP. Knowledge, attitudes and preferences regarding genetic testing for smoking cessation. A cross-sectional survey among Dutch smokers. BMJ Open. 2012 Jan 5;2(1):e000321. PubmedPMID: 22223839.

[5]. U.S. Department of Health and Human Services. How Tobacco Smoke Causes Disease: The Biology and Behavioral Basis for Smoking-Attributable Disease: A Report of the Surgeon General. Atlanta, GA: U.S. Department of Health and Human Services, Centers for Disease Control and Prevention, National Center for Chronic Disease Prevention and Health Promotion, Office on Smoking and Health, 2010.

[6]. Kubota T, Nakajima-Taniguchi C, Fukuda T, Funamoto M, Maeda M, Tange E, et al. CYP2A6 polymorphisms are associated with nicotine dependence and influence withdrawal symptoms in smoking cessation. Pharmacogenomics J. 2006 Mar-Apr;6(2):115-9. PubmedPMID: 16402086.

[7]. Benowitz NL. Nicotine addiction. N Engl J Med. 2010 Jun 17;362(24):2295303. PubmedPMID: 20554984.

[8]. United States Public Health Service Office of the Surgeon General; National Center for Chronic Disease Prevention and Health Promotion (US) Office on Smoking and Health. Smoking Cessation: A Report of the Surgeon General [Internet]. Washington (DC): US Department of Health and Human Services; 2020. PubmedPMID: 32255575.

[9]. Knott V, Heenan A, Shah D, Bolton K, Fisher D, Villeneuve C. Electrophysiological evidence of nicotine's distracter-filtering properties in non-smokers. J Psychopharmacol. 2011 Feb;25(2):239-48. PubmedPMID: 19939874.

[10]. Hughes JR, Hatsukami D. Signs and symptoms of tobacco withdrawal. Arch Gen Psychiatry. 1986 Mar;43(3):289-94. PubmedPMID: 3954551.

[11]. Hughes JR. Clinical significance of tobacco withdrawal. Nicotine Tob Res. 2006 Apr;8(2):153-6. PubmedPMID: 16766409.

[12]. Quaak M, van Schayck CP, Knaapen AM, van Schooten FJ. Genetic variation as a predictor of smoking cessation success. A promising preventive and intervention tool for chronic respiratory diseases? EurRespir J. 2009 Mar;33(3):468-80. PubmedPMID: 19251795.

[13]. Chen LS, Bloom AJ, Baker TB, Smith SS, Piper ME, Martinez M, et al. Pharmacotherapy effects on smoking cessation vary with nicotine metabolism gene (CYP2A6). Addiction. 2014 Jan;109(1):128-137. PubmedPMID: 24033696

[14]. Taylor DH Jr, Hasselblad V, Henley SJ, Thun MJ, Sloan FA. Benefits of smoking cessation for longevity. Am J Public Health. 2002 Jun;92(6):990-6. PubmedPMID: 12036794.

[15]. Sullivan PF, Kendler KS. The genetic epidemiology of smoking. Nicotine
Tob Res. 1999;1Suppl 2:S51-7; discussion Suss. PubmedPMID: 11768187.

[16]. Lerman C, Jepson C, Wileyto EP, Epstein LH, Rukstalis M, Patterson F et al. Role of functional genetic variation in the dopamine D2 receptor (DRD2) in response to bupropion and nicotine replacement therapy for tobacco dependence: results of two randomized clinical trials. Neuropsychopharmacology. 2006 Jan;31(1):231-42. PubmedPMID: 16123753.

[17]. Duan J, Wainwright MS, Comeron JM, Saitou N, Sanders AR, Gelernter J, et al. Synonymous mutations in the human dopamine receptor D2 (DRD2) affect mRNA stability and synthesis of the receptor. Hum Mol Genet. 2003 Feb 1;12(3):205-16. PubmedPMID: 12554675.

[18]. Chen LS, Baker TB, Piper ME, Breslau N, Cannon DS, Doheny KF, et al. Interplay of genetic risk factors (CHRNA5-CHRNA3-CHRNB4) and cessation treatments in smoking cessation success. Am J Psychiatry. 2012 Jul;169(7):735-42. PubmedPMID: 22648373.

[19]. Dubroff JG, Doot RK, Falcone M, Schnoll RA, Ray R, Tyndale RF, et al. Decreased Nicotinic Receptor Availability in Smokers with Slow Rates of Nicotine Metabolism. J Nucl Med. 2015 Nov;56(11):1724-9. PubmedPMID: 26272810.

[20]. Ware JJ, Aveyard P, Broderick P, Houlston RS, Eisen T, Munafò MR. The association of rs1051730 genotype on adherence to and consumption of prescribed nicotine replacement therapy dose during a smoking cessation attempt. Drug Alcohol Depend. 2015 Jun 1;151:236-40. Pubmed PMID: 25891233. 